\title{
The Significance of the Process of Music Therapy for Children with Multiple Social and Communication Disabilities: Case Studies
}

\author{
Sara Marta Knapik-Szweda ${ }^{1}$ * \\ 1 University of Silesia, Faculty of Pedagogy and Psychology, Department of Children's Creativity Expression \\ in Pedagogy, Katowice, Poland \\ *knapik.sara@gmail.com
}

Received: 19 September 2017 Accepted: 13 June 2018 Published: 1 March 2019

Editor: Juanita Eslava-Mejia Reviewers: Douglas Keith, Tali Gottfried

\begin{abstract}
Music therapy is an interdisciplinary branch of science and a form of therapy which enables establishing contact with every human being by means of an aesthetic sound message. The aim of this paper is to present the influence of music therapy procedures on communicative and social areas of the development of children with multiple disabilities, namely two boys. Moreover, the research activity is also concentrated on the ways music influences particular cases, namely which chosen music therapy strategies. The article presents individualizing research in a qualitative dimension. The outline of the research project is presented with its problem matters, research objectives, methods (of individual case study), and research techniques, as well as a detailed description of the research tool - The Individualized Music Therapy Assessment Profile (IMTAP) recommended by the American Music Therapy Association (AMTA). The results presented in a detailed description and observation schedule as well as data collected from interviews demonstrates and, at the same time, answers the research question that music therapy is a useful and effective form of therapy in the case of two boys with multiple disabilitities - to improve social and communicative functioning of the their development.
\end{abstract}

\section{Introduction}

Music therapy (MT) is an interdisciplinary field of science and form of therapy, nowadays increasingly popular, which creates the possibility of comprehensively influencing each individual. It has a large psychological, medical, and pedagogical potential utilized for numerous supportive and therapeutic actions. The richness of means, techniques, methods, and approaches in the field of music therapy makes it possible to adjust actions to the needs, habits or interests of the participants of therapy (Wheeler, 2015).

The essence of MT is the relationship that develops between a participant and a therapist, built on the foundation of musical properties (various musical elements, such as: melody, rhythm, harmony, dynamics, tempo, colour and articulation, Nordoff, Rob- 
bins, 2007). The above-mentioned elements form an inseparable whole, thus making music a strong therapeutic tool. "Its strength consists in its elastic, polysemous, multi-style and multi-genre nature" (Stachyra 2012, p. 62, all quotations are rendered by a translator). A proper comprehension of music and its meaning in the therapeutic process is crucial, since music constitutes a non-verbal channel of communication with the world - it crosses verbal barriers and is understood simultaneously on multiple levels (Stachyra, 2012). Tadeusz Natanson (1978,, the "father" of Polish music therapy) defined MT as, "a method of behaviour that utilizes the manifold influence of music on the psychosomatic system of a human being on multiple levels" (p. 51). Natanson thus referred to the very essence of music and its influence on an individual.

The World Federation of Music Therapy ${ }^{1}$ gives a detailed definition of MT and emphasizes its comprehensive approach to an individual; the approach aims to meet the "psychological, emotional, mental, social and cognitive needs of an individual" as part of the process of fulfilling the designated therapeutic purpose (Stachyra, 2009, p. 62). That is why it plays such a major role in case of people with multiple disabilities who are the subject of this study.

According to the definition, a person with multiple disabilities is a person with at least two disabilities caused by one or numerous factors in various periods of time (Twardowski, 2009, p. 290). The high number of disabilities and their complexity often results in the lack of verbal and social communication, movement, or emotional disorders. Frohlich (1998) described people with multiple disabilities as restricted in terms of overall functioning - on the physical, emotional as well as cognitive level (p. 11-12). He characterized the specificity of these people's needs and their fulfilment, which arises from the degree and multitude of overlapping restrictions. He enumerated the need for closeness in order to experience the surrounding reality; the need to be helped by a teacher or a therapist in order to establish contact with the world; and the need of a person who understands, cares, and establishes contact despite the lack of unambiguous communications (p. 14-15). Kielin (2014) emphasized that the primary need of each person, regardless of their disability, is the need to communicate, which is more important than physiological needs such as eating or drinking (p. 20). Moreover, he stressed that the therapist's responses to the child's messages, the pace adjusted to the child's pace and forming attunement or matching to the communicative forms between the therapist and the child are the bases for pre-intentional communication. Communication is extremely important at all stages of life. Its lack disturbs social relations and the child's ability to express their intentions, choices, or needs. MT can turn out to be extremely helpful in that area (Klein, 2014, p.14).

Diverse forms of work in the field of music therapy and a properly adjusted attitude of the therapist ensure the possibility of matching the actions with the most crucial needs of an individual and thus, fulfilling the therapeutic purposes on the level of communication or social development (McLaughlin \& Adler, 2015). Thanks to varied music therapeutic experiences, the participant may achieve therapeutic goals. These experiences are as follows: improvisation, recreating, composition, and listening (Bruscia, 1998).

The first experience, improvisation, involves a spontaneous creation without preparation. The creation can be vocal, instrumental, vocal and instrumental, or movement-related. The therapist's task is to instruct the participant and to demonstrate and inspire them to undertake a musical activity. There are two techniques of improvisation: imitating and accompanying (Wigram, 2007). Imitating involves the music therapist empathically copying the actions of the participant- the musical expression, body movements, behaviour, and reactions. Imitating allows the child to understand that the therapist wants to meet on the child's level of perception and consciousness via the means of musical synchronization. After a while, the child begins to notice the therapist's actions and gradually allows them to establish an interaction. The technique of accompanying, on the other hand, is supporting in nature. It makes it possible to form a frame where the child takes on the role of a soloist. The therapist provides a rhythmical, harmonious, or melodious background to the participant's musical actions 
- this accompaniment is an expression of the therapist's acceptance and empathy. Such actions make the participant feel important, appreciated, and make it possible to play more freely and confidently, while concentrating on creating.

The processing and recreating of music belong to the second experience of MT (Bruscia, 1998, p. 116-125).These are carried out by singing together known or lesser-known songs or recreating them by playing various instruments. The purposes of processing and recreating are to shape the abilities to cooperate, encourage sharing of emotions, express changeable desires and emotions, by recreating, and possibly modifying the musical material, develop the cognitive zone, and improve performance in that area (e.g. concentration, memory or other thought-related processes but also achieve better communication and integration in a social group).

The third experience- composition - involves the participant writing the lyrics to known songs, composing songs or works. Through composition, the participant improves communication with the group and the therapist and explores their own emotions, values, ideas, and thoughts.

The fourth experience of musical therapy is listening, which can be associated with relaxation and visualization. Its purpose is to relax and stimulate the participant. An individual develops the ability to listen, concentrate, activate imagination and projection by listening to diverse music (Bruscia, 1998, p. 116-125).

\section{The Subject Matter and Range of the Study}

This article is both a description and a summary of the project that studied the potential usefulness of music therapy as a tool in working with children with multiple disabilities. Since this field was only studied to some minor extent, the project was qualitative in nature and focused on two cases. Its purpose was to assess the effects of actions related to MT on the communication and social skill domains of development of the participating children. The research was also directed at determining the way music influences various cases, that is - exploring which of the MT strategies (improvisation, recreating, composition, and listening) influence the development of communicative and social abilities and skills of the participating children.

\section{The Methodological Characteristics of the Study}

The author's research perspective was based on a naturalist paradigm. The main task of studies of this type was an overall cognition of an individual, understanding their psychological and physical traits (Juszczyk, 2013, p. 96-97). Behaviours or reactions caused by specific actions or in other words, the details of the therapeutic process, are emphasized (Creswell 2013). In this case, music therapy is the acting agent. Crucial factors of a phenomenological qualitative study constitute the changes arising from the individual's experience and the interactions between the participant and the researcher (Creswell, 2013).

The objective of this research was to support the communicative and social development of two children with multiple disabilities, including visual and hearing impairments, through MT. The purpose of this research was to investigate the effectiveness of music therapy on the communication and social skill domains of development among children with multiple disabilities and present the programme of MT-based techniques, as well as the methods verifying their applications (detailed reports of the sessions and audio/video recordings of the research process). The following questions guided the study:

- What is the effectiveness of MT in improving the development of a child with multiple disabilities?

- How does MT benefit the communication ability of children with multiple disabilities?

- How does MT benefit the level of social behaviours of children with multiple disabilities? 
- Which MT techniques contribute to the improvement of communication ability and social skills in individual cases?

In her work, the author applied the following procedures: a) individual case method, also known as the individual case study (Krasoń \& Konieczna-Nowak, 2016); b) systematic and direct observation, whilethe researcher collected data by means of continuous observation and by participating in the events (Juszczyk, 2005);c) structured observationwas maintained, while the researcher took into account the precisely defined categories of a child's reactions or behaviour(Łobocki, 2011); d) informal overt interview(Gilroy, 2009, p. 154) was conducted with the parents of the participating children, informing the respondents of the interview, although not of its purpose (Juszczyk, 2013, p. 145); e) semi-structured interviews were conducted, while the researcher had a prepared set of questions but also took into account the freedom and openness of conversations, asked additional questions not specified in the list, allowed the elaboration on some answers and introduction of new subjects (Gilroy 2009, p. 154). Crucial techniques used in the project also included the in-depth analysis of documents and content analysis, whichrevealed musical and non-musical behaviors of the clients (Gilroy 2009).

The main data collection tool was the Individualized Music Therapy Assessment Profile (IMTAP; Baxter et al., 2007). The IMTAP is recommended by the American Music Therapy Association (AMTA) as a basic tool for monitoring the changes brought on by the MT intervention and assessing its results. The IMTAP is meant to assess the current developmental level of a patient/client in all domains of development. It finds an application in assessing both children and adults. In her research project, the author analyzed three areas of functioning of the studied cases: the communication area, divided into Receptive Communication (RC; auditory perception) and expressive communication (EC) areas, as well as the social skills (SOC) area (Baxter, et al. 2007, p. 57-78).

The area of Receptive Communication (RC)comprises with the awareness of sounds and silence, positioning the head or looking towards the source of a sound, imitating simple musical motives, following orders, reactions to changes in music, singing/vocalization and rhythmicality. The area of Expressive Communication (EC)comprises all the client's attempts at communication, including eye contact, facial expressions, gesticulation, signs, alternative and supporting communication, and vocalizations. The third area ofSocial Skills (SOC)includes reacting to hearing one's own name, being interested in activities, indicating a common area of focus, correctly interacting with the therapist, alternate actions. Data analysis focused on the occurrence or the lack of the occurrence of a given behaviour in a specific domain (Baxter et al., 2007).

Further on, the author will present the profiles of two boys with multiple disabilities, elaborate on the forms of music therapy applied in their cases and describe the analysis of the MT interventions in the light of its significance to the development of the communication and social skill of these children.

\section{Case Studies}

The current research project ${ }^{2}$ was conducted during 2014-2015 and included two participating children with multiple disabilities. Karol participated in individual MT sessions in his kindergarten from September 2014 to June 2015 (35 sessions) and Piotr participated in individual MT sessions conducted at his home from December 2014 to July 2015 (25 sessions). The weekly MT sessions of the two children lasted 30 to 45 minutes.

\section{Case I}

Karol was 4-years old at the time of the study. He got involved in numerous activities if they were pleasurable or interesting for him - frequently it was music. He had multiple disabilities, including epilepsy, encephalopathy, visual impairment, a serious heart 
defect (tetralogy of Fallot which resulted in multiple hospitalizations and was operated on three times), and low muscle tone (hypotonia). Karol's global development was significantly delayed. Music therapy in Karol's case was based on improvisation, singing familiar songs, and creating new vocal and instrumental arrangements.

\section{The first observation period}

During MT sessions Karol displayed the need for closeness, especially with a parent. Each time his parent left the room made him emotionally unstable, which made interactions with him much more difficult. Karol reacted positively to sounds and jingling objects, which prolonged his attention ability. Moreover, he became much livelier when he heard music. He displayed emotional disregulation during numerous activities.

Initially, Karol attended dyadic sessions with a parent, although he was not able to engage in musical activities, since he mostly displayed the need for closeness with the parent and attempted to cuddle. Over the MT process, he started to display interest in instruments which he put into his mouth, bit, looked at closely from all sides, used them to both produce strange sounds and discover new ways of making them - such behaviours occurred several times during a single session (SOC: A3 - showing interest in the activities presented ${ }^{3}$, A4 - displaying a shared area of focus) At times Karol pressed instruments (especially a guitar, a drum or a rattle) against his face and hit them for increased stimulation. He accepted instrument changes (SOC: B5 - accepting changes) and performed new actions associated with them (e.g. hit the drum's membrane, attempted to shake the rattle; SOC: B3 - finishing tasks within the time frame). The therapist established musical interaction with Karol and attempted to match his musical forms, which were short and chaotic, often impulsive. To draw Karol's attention to musical connection, the therapist made changes in rhythm, melody, or harmony (e.g. changes in musical idioms), and yet Karol did not seem to react. Karol was neither emotional, nor responsive for a musical relationship with the therapist.

At times during sessions, Karol seemed absent or unengaged. When withdrawn, he listened to the audio material created by the therapist (RC: A1 - shows awareness of sounds, silence) ${ }^{4}$ (SOC: E3 - accepting musical contact). During the a cappella vocal improvisations (singing without the accompaniment of an instrument), the client sometimes angled his head towards the source of the sound (RC: A3 - glances at/observes the sound source). Karol's musical actions (including playing simple instruments) were mostly based on auto stimulating actions that prevented him from establishing a connection with the therapist. During these musical productions he displayed significant rhythmicality and the ability to repeat fixed rhythmical patterns - he preserved the same intervals between each sound played, which can signify a well-developed sense of hearing (RC: A5 - imitates simple musical motives), (RC: E1 - plays at the same pace as the therapist, matching at least one beat to the 4/4 metre), (SOC: C1 - prediction of one own movement during sessions with the therapist). During initial sessions, Karol created short vocalizations. They took on the form unrelated to the therapist's musical material, therefore were most probably an unconscious product (EC: E3 - vocalizations are subconscious) ${ }^{5}$, non-imitative in nature (EC: D2 - vocalizations are not imitative). When the therapist initiated the vocalizations, Karol reacted with his own vocalizations with a significant delay (EC: E4 - vocalizations appear with delays); at the same time, his vocalizations diverged from typical speech in terms of speed and fluency (EC: E5 - vocalizations stray form the speed and fluency of typical rhythmical speech).

\section{The second observation period}

The change occurred in March of 2015, when Karol, in his constant difficulties to concentrate, began to notice the therapist's musical responses, thus broadening his own awareness regarding another person, the environment, or musical activities (RC: A1 -shows awareness of sounds, silence). Karol's playing on the instruments (initially short) became stable, rhythmical, and conscious (RC: A5 - imitates simple musical mo- 
tives; E1 - plays at the same pace as the therapist, matching at least one beat to the 4/ 4 metre; E2 - imitates simple rhythmical schemes). During the sessions there were moments when Karol put his hands against the guitar and listened attentively to its sound, concentrating on it for a longer period of time (SOC: A3 - showing interest in the activities presented). Free creation using instruments (instrumental improvisations) and sharing an instrument with the therapist (especially a drum, a guitar or a piano; SOC: A4 - displaying a shared area of focus) resulted in Karol maintaining contact with the therapist longer (SOC: A2 - showing awareness of the therapist's presence). During joint musical activities, Karol displayed increasing awareness of changing musical elements such as pace, melody or mood of a given material (RC: C1 - shows awareness of major changes in pace; C2 - shows awareness of major changes on melody; C5 - shows awareness of major changes in mood).

An important social and communicative factor obtained by Karol during these sessions was the ability to exchange musical material with the therapist. He hit the drum and waited for the therapist's response. Karol initiated a musical contact, which influenced him positively in terms of emotions - the fact confirmed by his smile, increasing motivation, and involvement in musical actions. Sometimes during the sessions, Karol became a musical leader. He also became more and more active in singing and in vocalizations based on vowels $a, o, u, i$ and the phrase dada (EC: C1 - vocalizations show quality in terms of the key; C2 - vocalizations adjusted to the dynamics of musical activities; C3 - vocalizations of a moderate range of melodies). The vocalizations lasted longer. During the last session, the therapist sometimes paused in his playing and waited for Karol's response, which took on a vocal form. Vocalizations were caused by audio stimulation (the therapist singing the boy's favourite song or an instrumental improvisation; RC: D1 -vocalizes in response to an audio stimulation; D6 - vocalizes in response to specific musical styles/idioms) and were a response to the therapist's singing (RC: D3 -vocalizes in response to the non-melodious instruments) or took on the form of free vocal improvisations with the therapist (EC: D1 - the participants vocalizes together with the therapist). The free vocal improvisations were not imitative in nature (EC: D2 - vocalizations are not imitative) but rather were mostly schematic (EC: E6 - vocalizations are schematic) and diverged from the pace and fluency of typical rhythmical speech (EC: E5 - vocalizations stray form the speed and fluency of typical rhythmical speech), however they also occurred much more frequently than during the beginnings of therapy.

Yet another factor influencing Karol's awareness of the surroundings was the need to choose the activity for the session (SOC: E11 - playing the role of leader in an activity). This occurred with the help of large images (the Picture Communication System, PCS - a form of alternative communication; Kaczmarek, 2015; EC: A1 -attempts at communicating; A3 - communicating needs and desires) that depicted appropriate activities (e.g. hugging; EC: A5 - communicating emotional states and the development of ideas), items (e.g. a swing) or instruments (a guitar or a drum). Thanks to the music therapist's cooperation with a specialist in the field of alternative communication, symbols that enabled the boy to consciously establish relations with the environment were introduced to the therapy, thus making it possible for him to decide on his preferences or activities (SOC: B4 - when possible, initiating new activities by the participant). The application of these symbols resulted in the formation of a specific structure of actions, which increased Karol's awareness of the therapeutic situation and the changes occurring during sessions (SOC: A10 - presenting the understanding of rules and structure of activities; A12 - displaying signs of the knowledge of the therapeutic situation ; B5 - accepting changes; B6 - participation in structured sessions).The increase in musical engagement might indicate better sensory integration and the sense of security in the relation with the therapist (SOC: E6 -maintaining musical interaction). Karol's later activities and his relationship with the therapist - based on trust - gradually lead the child to achieve independence in making choices and decisions, which resulted in the boy's growing development possibilities (SOC: A5 - establishing proper interactions with the therapist). Karol was also able to perform alternating actions, especially 
in rhythmical playing on the drum or the guitar's resonator (SOC: C1 - prediction of one's own movement during sessions with the therapist; C3 - sustaining the alternation using hints; E5 - imitating the therapist's play). It is during such improvisational actions that Karol awaited the therapist's response (SOC: C4 - waiting for the therapist's response in the correct moment; D2 - maintaining focus in relation to the therapist), which shows a growing ability to maintain reciprocity in his relationship with the music therapist. The ability to exchange rhythmical beats, which much less frequently took on the form of stimulation, also manifested itself in playing simultaneously with the therapist (SOC: E4 - playing in parallel/simultaneously to the therapist; E8 - cooperating with the therapist). Recreating client's favourite songs (e.g the welcome song enumerating various body parts or the farewell song) and the shared area of focus directed at performing them, (RC: A4 - differentiates between two various sounds; SOC: A6 - participation in structured sessions; A7 - being flexible in the development of musical activities without refusal or discomfort/stress) resulted in Karol's communicating with the therapist, and in consequence, also his kindergarten group, with much more motivation and joy (SOC: A9 - working to identify the therapeutic purposes during the sessions). He also accepted the therapist's help in leading and aiding him in showing activities associated with a song well-known to him (SOC: E1 - accepting a controlled interaction; E2 - accepting changes in a controlled interaction; E10 - showing flexibility when playing a known musical structure). The relationship between the therapist and Karol was strong enough for the child to express it with a hug or a smile (SOC: E13 - showing the skills to express a social relationship). During the sessions, Karol's activeness increased significantly and improved his well-being.

According to the interview ${ }^{6}$ with Karol's mother, she emphasized that during the MT sessions, the changes in the communication, social, motor and emotional skills as well as the change in the communication ability were the most important to both her and her child. She perceived Karol's musical communication, his ability to imitate vocally or instrumentally (Karol repeating the rhythmical beats to the drum - during initial sessions - with his leg, later - with his hand; a major improvement in vocalization, which made the boy enjoy making various sounds; the introduction of PCS to the music therapy sessions) as part of this communication. Joint vocal and instrumental improvisations were described by her as dialogues, wherein she observed the cooperation and alternating nature of the child's and the therapist's actions (social aspect). At the same time, she emphasized the crucial role of the therapist's approach, methods of reaching the child and interactions established as well as the therapist himself ("many things depend on the therapist"). The child's mother also stressed that music therapy positively influenced her son's emotions. It helped develop the ability to "vent bad emotions" redirecting the child's attention to his favourite songs, which make him smile and cause him to relax ("emotional balm"). In the mother's opinion, MT increased his mobility, developed manipulation in small motor skills (using instruments), and in gross motor skills (all movement-related actions, dancing with each other, marching to music). Karol's mother noticed that due to the deficit of sight, he treats hearing as compensation. Music therapy enabled him to develop it and assimilate new sounds. His mother commented, "Music therapy is beneficial. Very beneficial. There's no way we'll resign. This music will help him and will accompany him."

In Karol's case, the experiences of improvisational music therapy and singing familiar and popular songs significantly improved his social and communication skills. Continuing them may not only deepen his competence but also may lead to him gaining new abilities - both in terms of communication and social skills.

\section{Case II}

Piotr $^{7}$ was 4-years old at the time of the study. He showed great musical sensitivity. He was interested in music, the more so, in the course of the process, music became for him an important element of communication with the world. He was diagnosed with refractory epilepsy, polymorphic seizures, and hypoxic-ischemic encephalopathy. He 
was born a completely healthy child, but a bacterial infection in a hospital caused a serious damage to his brain and resulted in the appearance of symptoms such as sight impairment and general developmental delays in communication, social, motor, and cognitive domains. Music therapy with Piotr was based on improvisational music therapy and the neurologic music therapy techniques (NMT), which is a music therapy model that advocates for using music elements to improve cognitive, sensory, and motor dysfunctions visible in neurological disorders in particular (Bukowska, 2012). The main assumptions of the method are based on a neurophysiological model of perception and music production. In music therapy interventions, the following sensory-motor techniques are used: therapeutic instrumental music performance (TIMP) and patterned sensory enhancement(PSE; Hurt-Thaut \& Johnson, 2016). TIMP involves playing musical instruments to exercise and stimulate functional movement patterns (Thaut, 2005). In this case, TIMP was used when the therapist chose to place the musical instruments below Piotr's hands. The second technique, PSE uses the rhythmic, melodic, harmonic, and dynamic acoustical elements of music to provide temporal, spatial, and force cues for movements that reflect functional exercises and activities of daily living (Thaut et al., 1991). PSE, in this case was used to regulate client's motor and emotional state.

\section{The first period of observation}

Piotr began individual music therapy at home in December 2014 and continues to this day. The sessions last approximately 45 minutes, although their length is always adjusted to the child's current physical and mental state.

MT with Piotr started with an in-depth analysis of his state and his reactions to musical actions. During the initial sessions, he was minimally active. Lack of willingness to establish any contact with the therapist was demonstrated. Despite his sight impairment, Piotr was closing his eyes (SOC: B2 - showing awareness of the therapist's presence), turning his head away (SOC: E12 - free use of skills related to independence and interdependence of the therapist; EC: A1 - attempts at communicating; EC: B2 - gesticulations), tried to withdraw, remaining inactive, which could suggest he was aware of what was going on around him (RC: A1 - shows awareness of sounds, silence). He showed no reaction to the appearing instruments (guitar, drum) and the therapist's voice. However, he was not visibly resistant - he "surrendered" to all the therapist's actions without defiance. He seemed indifferent, but at the same time accepted being steered during all musical actions, e.g. when the therapist directed his hand to the guitar's strings, the drum's membrane or pressed his hand against the guitar to make him feel the instrument's vibrations (SOC: E1 - accepting a controlled interaction; E2 - accepting changes in a controlled interaction). Vocalization was very short (approx. 2 seconds) and resembled a sigh (EC: D2 - vocalizations are not imitative), but the child's behaviour indicated that, despite its shortness, he was aware of it (EC: E3 - vocalizations are subconscious).

During the first three sessions, Piotr reacted to sounds with a certain degree of oversensitivity, since each unexpected musical stimulus provoked a short epilepsy fit. At that time, during the sessions, Piotr was continuously monitored. This enabled the therapist to observe and recognize the child's reactions to the instrument being used, its volume, way of making sounds, the musical phrase produced by the therapist and each of the therapist's movements and actions. For the good of the child, the therapist had to adapt to each, even the smallest, movement of the child, therefore most of his actions were direct results of the observed physiological activities of the child - the regularity of his breathing, turning his head to the sides, or opening his eyelids. The therapist followed such signals, applied appropriate improvisation techniques (imitation and accompanying; Wigram 2004), and could turn Piotr's musical and non-musical activities into their joint musical material. During the improvisation, the therapist introduced a structure based on a repeating guitar accompaniment. As part of the accompaniment, at certain points the therapist created a pause in the music to increase the client's attention or observe his reactions to the lack of a musical stimulus. It has 
already been mentioned that during initial sessions Piotr was neither active and involved nor willing to establish contact. There were only moments when he opened his eyes when he heard a certain guitar phrase or moved his right hand more vigorously (RC: A4 - differentiates between two various sounds). In case of the latter, the therapist attempted to follow the child's hand by putting a drum under it to make Piotr aware to the purpose of his movements. The therapist did not introduce any diverse forms of musical expressions - such as wide range of the dynamics or idioms (containing differences in harmony and emotional tension) - knowing that each sudden change might cause an epileptic seizure.

\section{The second period of observation}

As time passed, thanks to regular therapy sessions and cooperation with the parents, Piotr's activeness gradually began to increase. His body movements became freer and his vocal activities, initially involving only grunting or muttering, turned into short vowel-based vocalizations. Piotr began to turn his head towards the source of the sound (RC: A2 - turns head towards the sound source) and became still after hearing new sounds, when receiving a new audio stimulus (RC: A3 - glances at/observes the sound source). The most important change to occur during the MT process was the decreasing frequency of epileptic events (obviously connected to the general improvement of Piotr's state, application of properly-selected medications and Piotr gradually becoming accustomed to the sessions). This made it possible for the forms of musical improvisation to become longer, more intense, and most importantly for Piotr to discover his freedom and desire to sing at his own discretion, by using his possibilities and skills - confirmed by the above-mentioned vocalizations, leg motions, or general body movements (SOC: A2 - showing awareness of the therapist's presence; B8 - appropriate development of activeness; EC: A1 - attempts at communicating; B2 - gesticulations). Such actions were Piotr's method of communication, perception, and interaction with the therapist.

Music therapy sessions in June and July indicated that Piotr's awareness of the therapeutic situation, the activeness and the structure of the sessions, was rising (SOC: A10 - presenting the understanding of rules and structure of activities; A12 - displaying signs of the knowledge of the therapeutic situation; B6 - participation in structured sessions). The following musical and non-musical behaviours were indicators of this awareness (SOC: A3 - showing interest in the activities presented): changing movements in response to a phrase sang by the therapist (RC: A1 - shows awareness of sounds, silence); all sound-related productions of the child: vocalizations, babbling, other specific creations occurring in response to singing (RC: D1 - vocalizes in response to an audio stimulation; D3 - vocalizes in response to the therapist's singing) or the therapist's repeating musical motive; Piotr's movements or vocalization in response to unfamiliar melodies (EC: B4 - combination of gesticulations and vocalizations; C1 - vocalizations show quality in terms of the key); adjusting the key of his own vocal creations to match the creations of the therapist (RC: D5 - vocalizes in response to melodious instruments; D8 - sings in the proper key with the therapist); increased concentration during rests (breaks in music; RC: C2 - shows awareness of major changes in melody). Gradually, Piotr joined the improvisation at his own free will, by filling in the rests, purposefully created by the therapist (RC: D9 - vocalizes during a musical rest initiated by the therapist; SOC: C4 - waiting for the therapist's response in the correct moment). Moreover, in these moments, Piotr found room for his own expression which resulted in the appearance of musical alternation (dialogue with the therapist) - the therapist presented short musical motives with a guitar accompaniment and paused in certain moments to wait for the child's response; there always was one, although after various periods of time (SOC: A5 - establishing proper interactions with the therapist; C1 - prediction of one's own movement during sessions with the therapist; C3 - sustaining the alternation using hints). Piotr's mother expressed her opinion in an interview, saying that these musical dialogues that she called "musical discussions" positively in- 
fluenced her child's communicative competence (SOC: E5 - imitating the therapist's play; E6 - maintaining musical interaction) as well as his well-being (smiling; SOC: A9 - showing attitude positive to others). Epileptic seizures occurred sometimes during the sessions, but after each such disruption, Piotr returned to the interrupted musical activities (SOC: D3 - returning to the interrupted activities, with hints, after disruptive actions). By analyzing the process of cooperation with the child, the therapist noticed a certain regularity in his behaviour - Piotr was vocally active when the accompaniment assumed the minor key of a given musical material (EC: C5 - vocalizations take on the length of sentences; SOC: E6 - maintaining musical interaction), at that time he also took on the role of a musical leader who, in specific moments, was independent from the therapist's musical material (RC: D6 - vocalizes in response to specific musical styles/idioms; SOC: E11 - playing the role of a leader in an activity; E12 - free use of skills related to independence and interdependence of the therapist; EC: D1 the participant vocalizes together with the therapist). As time passed, the number of sounds in his vocalizations visibly increased (Piotr smoothly went from a single vocalization to two or even three sounds, e.g. ahh, ooo, oogahh; EC: E5 - vocalizations stray from the speed and fluency of typical rhythmical speech), and his concentration level was higher than in any other form of musical accompanying (a similar phenomenon of preferring certain musical activities also occurred with Karol; SOC: A4 - displaying a shared area of focus; A9 - showing attitude positive to others; D1 - maintaining the length of focus; D2 - maintaining focus in relation to the therapist; EC: C4 - vocalizations take on the length of word phrases).

The nature of the improvisations (especially during the last sessions) was nostalgic. Phrases were mostly based on several sounds occurring in one-second intervals (EC: C3 - vocalizations of a moderate range of melodies), but sometimes the therapist presented intervals of a wider range, e.g. sixth, seventh, imitated by the boy after a while (RC: A4 - differentiates between two various sounds; D11 - imitates rising musical intervals higher than the major second; D14 - imitates gradually rising musical motives with an interval range greater than a second, immediately after hearing them; SOC: E10 - showing flexibility when playing a known musical structure). Piotr emanated the desire to express himself - when the therapist increased the dynamics of improvisation, the child's voice became significantly stronger (RC: C3 - shows awareness of major changes in dynamics; SOC: E8 - cooperating with the therapist; EC: C2 - vocalizations adjusted to the dynamics of musical activities). In the child's vocalization, a fragmentation of rhythmical values, which made the impression of increasing the pace and the dynamics of improvisation, could be heard (SOC: B4 - when possible, initiating new activities by the participant). Clear rhythm-emphasizing accents were also obvious. Piotr's vocalizations were at times imitative (EC: D3 - imitative vocalizations) and at times, depending on his state, delayed (EC: E4 - vocalizations appear with delays). The therapist attempted to encourage his movements, especially small motor skills. She often placed his hands on various instruments to help him sensorily experience them and their sounds (SOC: E1 - accepting a controlled interaction). These forms of musical involvement put the client not only in control over the execution, but also over the decision about the musical nature of all the actions undertaken with the therapist, which is a crucial developmental aspect in both the communicative and social sphere (SOC: C5 - maintaining alternation without hints; E3 - accepting musical contact).

The interview with Piotr's mother revealed that she noticed visible changes in her child's communication brought on by the MT interventions. The areas of change indicated by her included: becoming more sensitive, the joy heard in the sounds created, musical discussions, and the activation of the oral domain. Asked about the change in Piotr's social ability,his mother claimed the question was not so simple, since Piotr's social skills depend on his physical and mental state as well as the number and intensity of the seizures. The child's activeness during sessions - not only in the forms of vocalization or dialogues, but also the fact that he used his whole body (hands and legs) to play instruments was to his mother both an enormous positive surprise and, at the same time, a confirmation of the success of the music therapy. 
The mother emphasized that the time when her child began music therapy was hard for them, mostly due to the high number of seizures. One of her expectations for the MT was that "music would bring him calmness and pleasure." As it turned out, it gave him much more - not only calmness and joy but also improved his communication through the "musical discussions" and motor skills by activating his hands, legs, and whole body. Familiar songs, which were heard in his day-to-day life at home, sang or listened to with his parents (Four Elephants or a song about a crocodile in the Nile), and the vocal and instrumental improvisations used during the music therapy sessions were the forms of musical activities that contributed to the development of Piotr's social and communication domains.

When asked about the benefits of MT, Piotr's mother responded, "Music therapy is definitely a beneficial type of therapy. I absolutely recommend it, since it improves the development in its entirety [...]. Healthy children also have music, why should disabled children be deprived of it?" Continuing her response, the mother emphasized, "Music therapy is very important. I wouldn't say it's the most important, but it gives my child pleasure. He not only makes an effort during sessions, but also feels joy".

\section{Conclusions}

The results of the study briefly summarized in this article - presented in full in the detailed description and in the observation schedule - as well as the interview data, show that music therapy was a beneficial and successful form of therapy in case of both children with multiple disabilities. In both cases it positively influenced their musicality, resulting in visible changes - in Karol's case helping develop rhythmical skills, sustain rhythm, and imitate a rhythm; in Piotr's case - aiding in the development of sensitivity to melody, the ability to lead a vocalization in a given key, and the awareness of untangling musical phrases also in the form of vocalizations.

Aside from the improvements observed within the children's musical skills, non-musical goals were also addressed. In Karol's case, MT contributed to communicative changes such as: moving from withdrawal to noticing the therapist's musical responses, increasing awareness of another person, the environment or musical activities, becoming aware of the changing musical elements (the pace, melody or mood of a given material), and visible activeness in singing or vocalizations. Music therapy also reinforced the following social skills: free instrument-based creation of music (instrumental improvisations), sharing the instrument (especially the drum, guitar or piano) with the therapist while keeping the same area of focus or sustaining eye contact, positively reacting to song-based greetings and farewells with the boy understanding the meaning of the structure, initiating musical contact with the therapist and accepting the therapist when co-creating improvisations or songs, developing alternation, displaying the desire to work with the therapist, assuming numerous roles (e.g. the role of a leader or a follower), as well as the ability to express a social relation in the form of a hug, the sense of closeness to the therapist.

With Piotr, there were also changes in both development domains. In the communication domain these changes included: the awareness of sounds, silence, distinguishing sounds, sensitivity to changes in melody, dynamics, mood in the improvisations presented, vocalizations occurring as a response to the therapist's singing, the ability to imitate sounds and find appropriate moments for musical responses, and the willingness to establish and sustain communication via body movements. Within the social domain there were indications of changes such as: displaying interest in the activities and the growing desire to interact with the therapist during the vocal and instrumental alternations, the awareness of the structure of sessions or the therapist's presence, improving attention when making musical dialogues, and taking on numerous roles during improvisations (the role of a leader of the improvisation while the therapist becomes an accompanist, or the role of a person co-dependent on the therapist's musical material). 
Both Karol's and Piotr's musical behaviours translated to non-musical behaviours in the social and communication domains. The social domain included: alternation, maintaining focus, awareness of the interactions, and the musical dialogue in the structure of a conversation (one person creates, the other listens and receives). The communication domain included: the ability of a vocal and instrumental expression, the attempts to communicate through vocalization, body, gestures, imitation, as well as, the increasing motivation to express one's needs, ideas, emotional states and choices.

The benefits of MT appeared to be meaningful in both cases. In Karol's case the experiences of music therapy such as improvisation and recreating (singing familiar and popular songs) resulted in numerous benefits to the child's development confirmed by the description of the MT process and the interview with his mother. In Piotr's case, familiar songs (recreating) also applied outside of MT and vocal and instrumental improvisations with the use of a drum or a guitar (used during MT) were the forms of activity that contributed to the development of the social and communication domain.

\section{Discussion}

Music therapy was a beneficial form of therapy in the case of both children with multiple disabilities. Improvisational music therapy (Bruscia, 1998) and neurologic music therapy (Hurt-Thaut \& Johnson, 2016) facilitated an opportunity for the children to gain greater awareness, engage, and communicate better. These results support previous findings, indicating that improvisational music therapy may initiate communication, increase interaction with others, and increase reciprocal musical exchanges by responding to musical suggestions and initiating musical ideas (Goodman, 2007; Nordoff Robbins, 2007; Oldfield, 2006; Watson, 2007; Wheeler 2013). The research based on NMT focuses mainly on using musical elements in the treatment of people with Parkinson's disease (de Dreu, van der Wilk, Poppe, Kwakkel, \& van Wegen, 2012), with brain injury (Hurt, Rice, McIntosh, \& Thaut, 1998) and cerebral palsy (Baram \& Lenger, 2012; Howell, Flowers, \& Wheaton 1995; Kwak 2007). There are no clear studies referring to the usage of NMT techniques in the therapy of children with multiple disabilities.

The subjective nature of the qualitative study and its interpretative nature make it impossible to generalize and draw conclusions regarding the beneficial effect of music therapy on the communication and social skills of children with multiple disabilities. The study described here did not provide statistical generalizations and had no such ambitions (Flick, 2012, p. 81), but it allows the so-called internal generalization, which "stretches the conclusions of studies across a given group or situation" (p. 81).

Further studies on the subject, especially mixed projects utilizing the individualism and subjectivity of a qualitative study as well as the objectivity and accuracy of a quantitative study are required to develop and popularize MT as a form of therapeutic work with people with multiple disabilities. The study of the influence of music therapy on communication and social skills should also be expanded through the use of both standard and non-standard research tools in order to increase objectivity.

\section{Notes}

1. https://www.wfmt.info/WFMT/About_WFMT.html

2. The author has ethical clearance from University of Silesia in Katowice.

3. A numerical subcategory in a letter category on a given scale.

4. The Receptive communication (RC) observation schedule. The explanation and specific data can be found in appendix no. 1.

5. The Expressive communication (EC) observation schedule. The explanation and specific data can be found in appendix no. 2. 
6. The interview was conducted in the early 2016 with the consent of the boy's mother who also agreed for its audio recording. The fragments quoted are part of the transcript of the recorded interview, which is translated to English for the purpose of this manuscript.

7. Name has been changed to protect the client's anonymity.

8. The interview was conducted in the early 2016, with the consent of the boy's mother who also agreed for its audio recording. The fragments quoted are part of the transcript of the recorded interview, which were translated for the purpose of this manuscript.

\section{References}

Baram, Y., \& Lenger, R. (2012). Gait improvement in patients with cerebral palsy by visual and auditory feedback. Neuromodulation, 15(1), 48-52, https://doi.org/10.1111/ j.1525-1403.2011.00412.x.

Baxter, T., Berghofer, J. A., MacEwan, L., Nelson, J., Peters, K., \& Roberts, P. (2007). The individualized music therapy assessment profile. London, GBR: Jessica Kingsley Publishers.

Błeszyński, J. J., \& Baczała, (Eds.). (2014). Wybrane zagadnienia metody komunikacji alternatywnych $i$ wspomagajacych [The chosen aspects of augmentative and alternative methods of communication]. Poland: Wydawnictwo Naukowe Uniwersytetu Mikołaja Kopernika.

Bruscia, K. E. (1998). Defining music therapy (2nd ed.). Gilsum, NH: Barcelona Publishers.

Bukowska, A. (2012). Muzykoterapia neurologiczna. [Neurologic music therapy]. In K. Stachyra (Ed.), Modele, metody, podejścia w muzykoterapii [Models, methods, approach in music therapy]. Lublin, Poland: Wydawnictwo UMCS.

Creswell, J. W. (2013). Projektowanie badań naukowych. Metody jakościowe, ilościowe i mieszane [Design of research. Qualitative, quantitative and mixed methods]. Kraków, Poland: Wydawnictwo Uniwersytetu Jagiellońskiego.

de Dreu, A. S. D., Poppe, E., Kwakkel, G., \& van Wegen, E. E. H. (2012). Rehabilitation, exercise therapy and music in patients with Parkinson's disease: A meta-analysis of the effects of music-based movement therapy on walking ability, balance and quality of life. Parkinosonism and Related Disorders, 18, 114-119, https://doi.org/10.1016/ S1353-8020(11)70036-0.

Dykcik, . (2005). Pedagogika specjalna [Special needs education]. Poznań: Wydawnictwo Uniwersytetu im. Adama Mickiewicza w Poznaniu.

Flick, U. (2012). Projektowanie badania jakościowego [Design of quantitative research]. Warszawa, Poland: Wydawnictwo PWN.

Fröhlich, A. (1998). Stymulacja od podstaw [Stimulation from the beginning]. Warszawa: Wydawnictwa Szkolne i Pedagogiczne.

Gilroy, A. (2009). Arteterapia - badania i praktyka [Art therapy - Research and practice]. Łódź: Wydawnictwo Akademii Humanistyczno-Ekonomicznej w Łodzi.

Goodman, K. (2007). Music therapy groupwork with special needs children: The evolving process. Springfield, IL: Charles C. Thomas.

Howell, R. D., Flowers, P. J., \& Wheaton, J. E. (1995). The effects of keyboard experiences on rhythmic responses of elementary school children with physical disabilities. Journal of Music Therapy, 32, 91-112, https://doi.org/10.1093/jmt/32.2.91.

Hurt, C. P., Rice, R. R., McIntosh, G. C., \& Thaut, M. H. (1998). Rhythmic auditory stimulation in gait training for patients with traumatic brain injury. Journal of Music Therapy, 35, 224-241, https://doi.org/10.1093/jmt/35.4.228.

Hurt-Thaut, C., \& Johnson, S. B. (2016). Neurologic music therapy. In B. Wheeler (Ed.), Music therapy handbook (pp. 220-232). New York, NY: The Guildford Press.

Juszczyk, S. (2005). Badania ilościowe w naukach społecznych. Szkice metodologiczne

[Quantitative Research in the Social Sciences. Methodological Sketches]. Katowice:

Wydawnictwo Śląskiej Wyższej Szkoły Zarządzania im. gen. Jerzego Ziętka. 
Juszczyk, S. (2013). Badania jakościowe w naukach społecznych. Szkice metodologiczne [Qualitative research in the social sciences. Methodological sketches]. Katowice, Poland: Wydawnictwo Uniwersytetu Śląskiego.

Kaczmarek, B. B. (2015). Wstęp. [Introduction]. In B. B. Kaczmarek \& A. Wojciechowska (Eds.), Autyzm i AAC. Alternatywne i wspomagające sposoby porozumiewania się $w$ edukacji osób z autyzmem. Kraków, Poland: Wydawnictwo Impuls. [Autism and AAC. Augmentative and alternative communication in the education of people with autism].

Kielin, J. (Ed.). (2014). Rozwój daje radość. Terapia dzieci upośledzonych umysłowo $w$ stopniu głębokim [Development brings joy. Therapy of children with severe mental disability]. Sopot, Poland: Gdańskie Wydawnictwo Psychologiczne.

Kosakowski, C., Krause, A., \& Żyta, (Eds.). (2007). Osoba z niepełnosprawnościa w systemie rehabilitacji, edukacji $i$ wsparcia [Disabled persons in the system of therapy, education and support]. Olsztyn, Poland: Wydawnictwo Uniwersytetu Warmińsko-Mazurskiego.

Krasoń, K., \& Konieczna-Nowak, L. (2016). Sztuka, terapia, poznanie [Art, therapy and recognition]. Warszawa, Poland: PWN.

Kwak, E. E. (2007). Effect of rhythmic auditory stimulation on gait performance in children with spastic cerebral palsy. Journal Music Therapy, 44, 198-216, https://doi.org/10.1093/ jmt/44.3.198.

Łobocki, M. (2011). Metody i techniki badan pedagogicznych [Methods and techniques of pedagogical research]. Kraków, Poland: Oficyna Wydawnicza Impuls.

McLaughlin, B., \& Adler, R. F. (2015). Music therapy for children with intellectual disabilites. In B. Wheeler (Ed.), Music therapy handbook (pp. 277-289). New York, NY: The Guildford Press.

Natanson, T. (1978). Wstęp do nauki o muzykoterapii [[Introduction to music therapy]]. Wrocław-Warszawa-Kraków-Gdańsk: Zakład Narodowy im.

Nordoff, P., \& Robbins, C. (1971). Music therapy in special education. New York, NY: John Day Company.

Nordoff, P., \& Robbins, C. (2011). Clinical improvisation: Expanding musical resources. New York, NY: The Nordoff-Robbins Center for Music Therapy.

Nordoff, P., \& Robbins, C. (2007). Creative music therapy. A guide to fostering clinical musicianship. Gilsum, NH: Barcelona Publishers.

Oldfield, A. (2006). Interactive music therapy: A positive approach. Philadelphia, PA: Jessica Kingsley Publishers.

Pavlicevic, M. (2010). Music therapy in context. music, meaning and relationship. London, GBR: Jessica Kingsley Publishers.

Schwartz, E. (2008). Music therapy and early childhood: A developmental approach. Gilsum, NH: Barcelona Publishers.

Stachyra, K. (2009). Muzykoterapia i wizualizacja $w$ rozwijaniu kompetencji emocjonalnych studentów pedagogiki [Music therapy and visualization in the development of emotional competence of pedagogy students]. Lublin, Poland: Wydawnictwo Uniwersytetu Marii Curie-Skłodowskiej.

Stachyra, K. (Ed.). (2012). Podstawy muzykoterapii [The rudiments of music therapy]. Lublin, Poland: Wydawnictwo Uniwersytetu Marii Curie-Skłodowskiej.

Thaut, M. (2005). Rhythm, music and the brain. London, GBR: Routledge.

Thaut, M. H., Schleiffers, S., \& Davis, W. B. (1991). Analysis of EMG activity in biceps and triceps muscle in a gross motor task under the influence of auditory rhythm. Journal of Music Therapy, 28, 64-88, https://doi.org/10.1093/jmt/28.2.64.

Twardowski, A. (2009). Pedagogika osób ze sprzężonymi upośledzeniami. [Pedagogy of individuals with multiple disabilites]. In W. Dykcik (Ed.), Special Education (pp. 289-299). Poznań, Poland: Wydawnictwo Naukowe UAM. 
Watson, T. (2007). Working with people with profound and multiple learning disabilities in music therapy. In T. Watson (Ed.), Music therapy with adults with learning disabilities (pp. 98-111). Philadelphia, PA: Jessica Kingsley. https://doi.org/10.4324/9780203946541.

Wheeler, B. L. (2015). Music therapy as a profession. In B. Wheeler (Ed.), Music therapy handbook (pp. 5-16). New York, NY: The Guildford Press.

Wheeler, B. L. (2013). Individuals with severe and multiple disabilities. In M. R. Hintz (Ed.), Guidelines for music therapy practice in developmental health (pp. 399-434). Gilsum, NH: Barcelona Publishers.

Wigram, T. (2004). Improvisation. Methods and techniques for music therapy clinicians, educators, and students. London, GBR: Jessica Kingsley Publishers.

\section{Appendix}

Appendix 1: The Receptive communication observation schedule (personal elaboration on the basis of: Baxter et al. 2007, p. 57-78).

Appendix 2: The Expressive communication observation schedule (personal elaboration on the basis of: Baxter et al. 2007, p. 57-78).

Appendix 3: The Social skills observation schedule (personal elaboration on the basis of: Baxter et al. 2007, p. 57-78). 